\title{
South Indian River Ranking using Fuzzy Analytic Hierarchy Process
}

\author{
A. Rajkumar $^{1 *}$, M.Chandramohan ${ }^{2}$ \\ ${ }^{1}$ Department of Mathematics, A.V.V.M .Sri Pushpam College Poondi, Thanjavur, Tamilnadu, India \\ ${ }^{2}$ Department of Chemistry, A.V.V.M .Sri Pushpam College Poondi, Thanjavur, Tamilnadu, India
}

Available online at: www.isroset.org

Received: 26/Sept/2018, Accepted:10/Oct/2018, Online: 31/Oct/2018

\begin{abstract}
Nowadays, water resource management should be managed in integrated manner including water quality, water quantity, land use and economy, especially when we wanted to find the highest potential river to be developed for efficient use of water systems. Water resources planning and management should consider various aspects of river basins. Current river ranking techniques namely, water quality index, and national water quality standard were found to only consider water quality aspects. In this study a special focus is given on the method that deals with vague data which the decision making accounted during data acquisition. The river ranking problem is a strategic issue and has significant impact on the efficiency of a river system. On the other hand, the river ranking among many alternatives presents a multi-criteria decision Making (MCDM) problem. Hence, fuzzy set theory can be applied. Fuzzy Analytic Hierarchy Process (FAHP) technique is used to rank alternatives to find the efficient use of the river system. Fuzzy number and linguistic variable are used to in-currently vague data. Four criteria and twenty sub criteria and identify, tested and applied to real data. The FAHP is used to analyze the structure of the river ranking problem. A real world application is conducted to illustrate the utilization of the model using the valuable data pertaining to a six south Indian rivers. The application can interpreted as demonstrating the effectiveness and feasibility of the FHAP model.
\end{abstract}

Keywords: FAHP, MCDM, WQI, Triangular fuzzy Number.

\section{INTRODUCTION}

In many applications ranking of fuzzy numbers is an important component of the decision process. In addition to a fuzzy environment, ranking is a very important decision making procedure. Since Jain (29) employed the concept of maximizing set to order the fuzzy numbers in 1976, many authors have investigated various ranking methods. Some of these ranking methods have been compared and reviewed by Bortolan and Degani (34) and more recently by Chen and Hwang (43).Other contributions in this, fields include. An index for ordering fuzzy numbers defined by choobineh and lie (40) ranking fuzzy values with satisfaction function investigated by lee.e.t.al(42) ranking and defuzzification methods on area compensation presented by for tombs and robins(43) and ranking alternatives with fuzzy weights using maximizing set and minimizing set given by raj and Kumar (56) however, some of these methods, are computationally complex and difficult to implement, and others are counterintuitive and not discriminating. Furthermore, many of them produce different ranking out comes for the same problem. There are numerous multi criteria decision making (MCDM) techniques developed till date. One of the most common MCDM techniques is AHP, ([3]-[8]). The use of AHP will keep increasing because of the AHP's advantages such as ease of use, great flexibility, and wide applicability [3]. In this study, AHP will be used together with fuzzy set to solve river ranking problem. Numerous authors have presented different ranking methods to rank alternatives under fuzzy environment during the last two decades [8]. Bottani and Rizzi [9] used fuzzy logic to deal with vagueness of human thought and AHP to make a selection of the most suitable dyad supplier/purchased item. Buyukozkan et al. [10] had proposed fuzzy AHP method to evaluate e-logistics-based strategic alliance partners. Efendigil et al. [2] proposed two-phase model based on artificial neural networks and fuzzy AHP to select a third-party reverse logistics provider. Ca scales and Lamata [11] proposed fuzzy AHP for management maintenance processes where only linguistic information was available. Pan [12] used fuzzy AHP for selecting the suitable bridge construction method. Sheu [13], proposed a hybrid neuro-fuzzy methodology to identify appropriate global logistics operational modes used for global supply chain management. Tsai et al. [14] used fuzzy AHP for market positioning and developing strategy in order to improve service quality in department stores. Wu et al. [15] proposed fuzzy AHP for measurement of non-profit organizational performance. Huang et al. [16] applied fuzzy AHP to represent subjective expert judgments in government-sponsored R\&D project selection. Lee et al. [17] constructed fuzzy AHP to evaluate performance of IT department in the manufacturing industry in Taiwan. Chang C W et al. $[18,19]$ used fuzzy AHP to evaluate and control silicon wafer slicing quality. Chang and Wang [20] proposed consistent fuzzy preference relation in a comparison matrix. Chen 
et al. [21], proposed a combination of fuzzy AHP with multi dimensional scaling in identifying the preference similarity of alternatives. hen and Qu [22], proposed fuzzy AHP to evaluate the selection of logistics centre location. Dagdeviren and Yuksel [23] developed fuzzy AHP for behavior-based safety management. Nagahanumaiah et al. [24] used fuzzy AHP to identify problem features for injection mould development. Duran and Aguilo [25] used fuzzy AHP for machine-tool selection. Out et al [26]proposed a combined fuzzy AHP and fuzzy TOPSIS approach for machine tool selection problem. Yanget al. [27] proposed fuzzy AHP for Vendor selection by integrated fuzzy MCDM techniques with independence and interdependence. A significant finding from all the researchers is that they have used triangular fuzzy number (TFN) to represent vague data or linguistic information. It is important to note that the extent analysis method has been used by them [23] and [26] found that it cannot estimate the true weights from a fuzzy comparison matrix [28]

\section{NEW APPROACH FOR RANKING OF FUZZY NUMBERS.}

A fuzzy number $\mathrm{A}$ is a mapping $a(x): x \rightarrow[0,1]$ with the following properties.1. Ais an upper semi-continuous function on R.2. $A(x)=0$ Outside of some interval $\left[a_{1}, b_{2}\right]$ ( R.3. There are real numbers $a_{2}, b_{1}$ such as $a_{1} \leq a_{2} \leq b_{1} \leq b_{2}$ and, $A(x)$ is a monotonic increasing function on $\left[a_{1}, b_{2}\right], A(x)$ is a monotonic decreasing function on $\left[b_{1}, b_{2}\right], A(x)=1$ for all $x$ in $\left[a_{2}, b_{1}\right]$,let $R$ be the set of all real numbers. The researchers assume a fuzzy number A that can be expressed for all $X \in R$ in the form.

$\mathrm{A}(\mathrm{x})= \begin{cases}g(x) & \text { when } x \in[a, b) \\ 1 & \text { when } x \in[b, c] \\ h(x) & \text { when } x \in(c, d] \\ 0 & \text { otherwise }\end{cases}$

Where $a, b, c, d$ are real numbers such as $a<b \leq c \leq d$ and $\mathrm{g}$ is a real valued function that is increasing and right continuous and $\mathrm{h}$ is a real valued function that is

\section{DATA GATHERING}

Step 1: Determining objectives \& choosing alternatives.

This is done through literature survey and discussion with knowledgeable experts. During this step, we do the following:

- Define the problem clearly with specifications on its multi-criteria aspects.

- Determine the overall goal and sub-goals, identifying the evaluation criteria.

Step 2: Determining criteria to be used in the ranking process.

In this step, we identify the candidate's alternatives. This is done in confirmation with the knowledge experts. 4 criteria namely water quality, water quantity; land use and economy have been identified.20 sub-criteria namely biochemical oxygen demand (BOD), suspended solid (SS), PH, dissolved oxygen (DO), chemical oxygen demand (COD), ammonia nitrogen (AN), temperature, iron, flow rate, length of river, width of river, residence, industry(1), agriculture(1), forest, fishery, industry(2), recreation, agriculture(2) and reservoir have been chosen.

Step 3: Structuring decision hierarchy.

In this step, the decision problem is structured into a hierarchical model, in which the overall goal (usually the selection of the best alternative) is situated at the highest level; elements with similar features (usually evaluation criteria) are grouped at the same interim level and the decision variables (usually alternatives) are situated at the lowest level. Analytic Hierarchy process (AHP) is an MCDM method based on priority theory. It deals with complex problems which involve the consideration of multiple criteria alternatives simultaneously.

Step 4: Approved decision hierarchy.

Decision hierarchy is analyzed in detail. This study defines the evaluation criteria and sub-criteria using water quality index, quantity of water, land use and economical activity. The 4 criteria and 20 sub-criteria proposed are structured in a hierarchy and the final decision is made. The top level in the hierarchy is our goal to find the highest rank river for efficient use of water system. Second level in the hierarchy is the four criteria which are identified as water quality, water quantity, land use and economy. Third level in the hierarchy is the 20 sub-criteria identified in step 2. At the lowest level in the hierarchy are alternatives which present the six rivers in the comparison namely the Godavari, the Krishna, the Cauvery, the Tungabhadra, the Bharathapuzha and the Bhavani.

Step 5: Assigning weights to criteria and alternatives via FAHP.In this study, all criteria in the judgment matrix are given equal important weights and all sub criteria (alternatives) weight vectors are represented using objective value, which were obtained 
from field data collection. These data cannot be used directly into AHP since they are in different units and therefore data normalization must be done in advance. Some bigger values might be preferred and therefore they have higher priority in AHP but for certain sub-criteria, smaller values are preferred than bigger values. For water quality, the lowest value for BOD, COD, $\mathrm{AN}, \mathrm{SS}$, temperature and iron, the highest value of DO and the nearest value for $\mathrm{pH}$ are the highest priority in AHP. For a water quantity, the highest value for flow rate, the longest and the widest rivers have the highest priority value in AHP. For land use, the highest percentage of forest and the lowest percentage of residence, industry and agriculture are the highest priority value in AHP.

Fig.1: The structured hierarchy used in this study

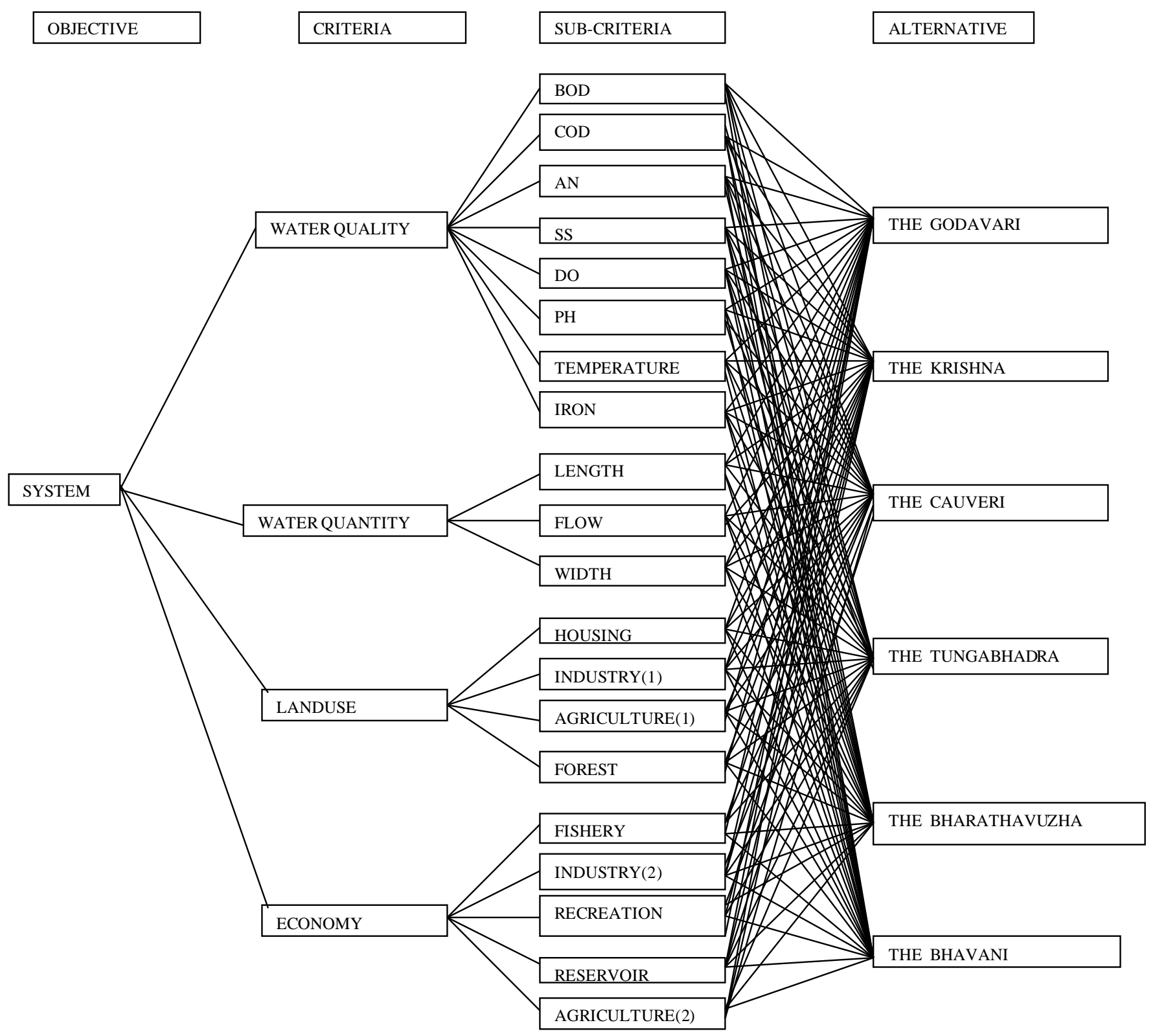

For a water quantity, the highest value for flow rate, the longest and the widest rivers have the highest priority value in AHP. 
For land use, the highest percentage of forest and the lowest It his study, we propose the three fuzzy parameters to represent conventional Saaty's AHP $1-9$ relative importance scale [29], given by means of the following equations

$\tilde{I} \equiv(1,1,1), \bar{x} \equiv(x-1, x, x+1) \forall x=2,3, \ldots, 8$ and $\overline{9} \equiv(9,9,9)$.

The TFN can express subjective pairwise comparison or presents certain degree of vagueness. We also propose linguistic variables that can be used by DMs to represent vague data should they feel uncomfortable with the triangular numbers.

The proposed TFN and linguistic variables related to Saaty's scale of preference values are

\begin{tabular}{|c|l|l|l|}
\hline $\begin{array}{l}\text { Saaty's scale of relative } \\
\text { importance }\end{array}$ & Definition & TFN & Linguistic variables \\
\hline 1 & Equal importance & $(1,1,1)$ & Least importance \\
\hline 3 & $\begin{array}{l}\text { Moderate importance of one over } \\
\text { another }\end{array}$ & $(2,3,4)$ & Moderate importance \\
\hline 5 & Essential or strong importance & $(4,5,6)$ & Essential importance \\
\hline 7 & Demonstrated importance & $(6,7,8)$ & Demonstrate importance \\
\hline 9 & Extreme importance & $(9,9,9)$ & Extreme importance \\
\hline $2,4,6,8$ & $\begin{array}{l}\text { Intermediate values between } \\
\text { Two adjacent judgments }\end{array}$ & $\begin{array}{l}(1,2,3), \\
(3,4,5), \\
\end{array}$ & $\begin{array}{l}\text { Intermediate values between two adjacent } \\
\text { judgments } \\
\end{array}$ \\
& & $(7,8,7)$ & \\
\hline
\end{tabular}

shown.Table.1.

Table 1.1: Proposed TFN and linguistic variables.

In a previous work, a difficulty arose in acquiring fishery activity data, since it could not be quantified. Point value was used to represent the value of relative importance between alternatives. However, these point values are not suitable for the DMs to give their preference judgments naturally. The proposed TFN or linguistic variables to represent vague data from previous work ([1], [30]) used in this study is shown in Table 1.1.

\begin{tabular}{|l|c|c|c|}
\hline Rivers name & Point value([1],[3] & TFN & Linguistic variables \\
\hline The Godavari & 4 & $(3,4,5)$ & Intermediate between 3 and 5 \\
\hline The Krishna & 4 & $(3,4,5)$ & Intermediate between 3and5 \\
\hline The Cauvery & 3 & $(2,3,4)$ & Moderate importance \\
\hline The Tungabhadra & 3 & $(2,3,4)$ & Moderate importance \\
\hline The Bharathapuzha & 2 & $(1,2,3)$ & Intermediate between 1and 3 \\
\hline The Bhavani & 1 & $(1,1,1)$ & Least importance \\
\hline
\end{tabular}

Table 1.1: Triangular fuzzy numbers and linguistic variables for fishery

Step 6: Approving weights used.

Weights have been approved by knowledge experts through the construction of a judgment matrix as well as weight vector $W$ for the hierarchical structure. The comparisons are used to form a matrix of pair wise comparisons called the judgment matrix $A$.

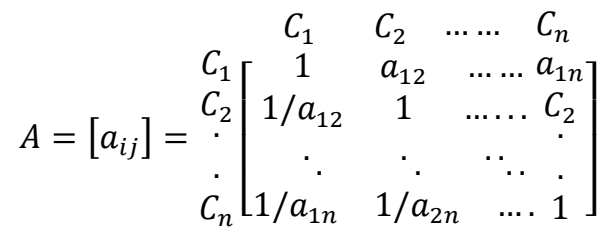

Each entry $a_{i j}$ of the judgement matrix is governed by three rules: $a_{i j}>0 ; a_{i j}=1 / a_{j i} ; a_{i i}=1$ for all i. The resulting weights of the elements may be called the local weights.After a judgement matrix has been built, any fuzzy data is then defuzzified and is performed using a method used by Chang [18, 19] as follows,

$$
\left(a_{i j}^{\alpha}\right)^{\lambda}=\left[\lambda \cdot L_{i j}^{\alpha}+(1-\lambda) \cdot U_{i j}^{\alpha}\right], 0 \leq \lambda \leq 1,0 \leq \alpha \leq 1
$$


Where, $L_{i j}=\left(M_{i j}-L_{i j}\right) * \alpha+L_{i j}$ and $U_{i j}=U_{i j}-\left(U_{i j}-M_{i j}\right) * \alpha$ and its reciprocal value can be calculated as below.

$$
=\frac{1}{\left(a_{i j}^{\alpha}\right)^{\lambda}}, 0 \leq \lambda \leq 1,0 \leq \alpha \leq 1, i>j
$$

Where, $\alpha$ display a decision maker's preference and $\lambda$ is risk tolerance. Initial value for both $\alpha$ and $\lambda$ is 0.5 to reflect normal preference and risk tolerance. When $\alpha=1$, the uncertainty range is the lowest and when $\lambda=1$, the DMs are pessimistic. Based on Table 3.2, when $\alpha$ and $\lambda$ is 0.5 , defuzzification is performed as follows:

$$
\begin{gathered}
L_{11}=0.5 *(4-3)+3=3.5 \\
U_{11}=5-(5-4) * 0.5=4.5, \\
a_{11}=[0.5 * 3.5+(1-0.5) * 4.5=4 .
\end{gathered}
$$

Eigenvalue and eigenvector have been calculated and a consistency check is performed using Saaty and Kearns's conventional AHP method [29]. Saaty and Kearns [29] proposed consistency index (C.I.) and consistency ratio (C.R.) to verify the consistency of the comparison matrix. C.I. and C.R. are defined as follows:

$$
\begin{array}{ll}
C . I=\frac{\lambda_{\max }-n}{n-1} & C . R=\frac{C . I}{R . I}
\end{array}
$$

Where, $\lambda_{\max }$ is the largest eigenvalue of the judgement matrix and $n$ is the number of elements and R.I is the random index for consistency of different order of random matrix. The value of C.R. should be around $10 \%$ or less to be accepted. According to Saaty and Kearns [29], in some cases, $20 \%$ of C.R can be tolerated but cannot be more than that. For all objective data used in this study, average value method is used. Table 1.3 - Table 1.6. present normalized (average) data which have been used in this method. clean, slightly polluted or polluted category and to classify the rivers into class $1,2,3$, 4 , or 5 based on water quality index and international water quality standards for south India respectively.

\begin{tabular}{|c|c|c|c|c|c|c|c|c|}
\hline Rivers Name & BOD & COD & AN & SS & DO & PH & Temp & iron \\
\hline The Godavari & 0.77 & 5.56 & 1.24 & 1.33 & 0.16 & 3.9 & 0.99 & 00 \\
\hline The Krishna & 31.75 & 118.95 & 123.36 & 23.37 & 0.19 & 1.9 & 1.04 & 41 \\
\hline The Cauvery & 3.98 & 12.04 & 18.08 & 27.76 & 0.06 & 0.9 & 0.95 & 27 \\
\hline $\begin{array}{c}\text { The } \\
\text { Tungabhadra }\end{array}$ & 2.29 & 8.71 & 18.77 & 13.06 & 0.03 & 2.9 & 0.97 & 95 \\
\hline $\begin{array}{c}\text { The } \\
\text { Bharathapuzha }\end{array}$ & 11.01 & 8.17 & 21.18 & 15.72 & 0.02 & 5.9 & 0.96 & 27 \\
\hline The Bhavani & 13.77 & 1.91 & 10.93 & 12.31 & 0.01 & 4.9 & 0.09 & 61 \\
\hline
\end{tabular}

Table 1.2: Data for water quality

\begin{tabular}{|c|c|c|c|}
\hline & Length & Flow & Width \\
\hline The Godavari & 0.01 & 0.03 & 0.07 \\
\hline The Krishna & 0.09 & 0.08 & 0.08 \\
\hline The Cauvery & 0.09 & 0.00 & 0.09 \\
\hline The Tungabhadra & 0.01 & 0.22 & 0.03 \\
\hline The Bharathapuzha & 0.01 & 0.01 & 0.05 \\
\hline The Bhavani & 0.04 & 0.66 & 0.09 \\
\hline
\end{tabular}

Table 1.3: Data for water Quantity

\begin{tabular}{|c|c|c|c|c|}
\hline & Resident & Industry(1) & Agriculture(1) & Forest \\
\hline The Godavari & 20.02 & 5.42 & 0.00 & 0.53 \\
\hline The Krishna & 129.77 & 12.61 & 212.67 & 0.09 \\
\hline The Cauvery & 0.09 & 0.95 & 0.09 & 0.00 \\
\hline The Tungabhadra & 8.26 & 0.09 & 0.00 & 0.00 \\
\hline The Bharathapuzha & 36.13 & 1.06 & 0.00 & 0.00 \\
\hline The Bhavani & 0.00 & 2.25 & 0.00 & 0.00 \\
\hline
\end{tabular}

Table 1.4: Data for land use 


\begin{tabular}{|c|c|c|c|c|c|}
\hline & Fishery & Recreation & Industry(2) & Agriculture(2) & Reservoir \\
\hline The Godavari & 0.09 & 0.04 & 0.09 & 0.01 & 0.03 \\
\hline The Krishna & 0.09 & 0.09 & 0.05 & 0.09 & 0.09 \\
\hline The Cauvery & 0.65 & 0.04 & 0.05 & 0.01 & 0.03 \\
\hline $\begin{array}{c}\text { The } \\
\text { Tungabhadra }\end{array}$ & 0.65 & 0.09 & 0.09 & 0.01 & 0.01 \\
\hline $\begin{array}{c}\text { The } \\
\text { Bharathapuzha }\end{array}$ & 0.04 & 0.04 & 0.09 & 0.01 & 0.01 \\
\hline The Bhavani & 0.15 & 0.04 & & 0.09 \\
\hline
\end{tabular}

Table 1.5: Data for economy

Alternatives can be calculated as follows: $A=\left[a_{i j}\right]_{m \times n}=\left[\begin{array}{cccc}a_{11} & a_{12} & \ldots & a_{1 n} \\ a_{21} & a_{22} & \ldots & a_{2 n} \\ \vdots & \vdots & & \vdots \\ a_{m 1} & a_{m 2} & \ldots & a_{m n}\end{array}\right]$

$$
W=\left[w_{i j}\right]_{1 \times n}=\left[\begin{array}{llll}
w_{1} & w_{2} & \cdots & w_{n}
\end{array}\right]
$$

$$
W^{T}=\left[\begin{array}{c}
w_{1} \\
w_{2} \\
\cdot \\
\cdot \\
w_{n}
\end{array}\right]
$$

Then, $S=A \otimes W^{T}=\left[\begin{array}{cccc}a_{11} & a_{12} & \ldots & a_{1 n} \\ a_{21} & a_{22} & \ldots & a_{2 n} \\ \vdots & \vdots & \vdots & \cdot \\ a_{m 1} & a_{m 2} & \ldots & a_{m n}\end{array}\right] \otimes\left[\begin{array}{c}w_{1} \\ w_{2} \\ \cdot \\ \cdot \\ w_{n}\end{array}\right]$

And

$$
\begin{aligned}
& S=A \otimes W^{T}=\left[\begin{array}{c}
a_{11} \otimes w_{1} \odot a_{12} \otimes w_{2} \odot \ldots \ldots \ldots \ldots \ldots \odot a_{1 n} \otimes w_{n} \\
a_{21} \otimes w_{1} \odot a_{22} \otimes w_{2} \odot \ldots \ldots \ldots \ldots \ldots \odot a_{2 n} \otimes w_{n} \\
a_{m 1} \otimes w_{1} \odot a_{m 2} \otimes w_{2} \odot \ldots \ldots \ldots \ldots \ldots \odot a_{m n} \otimes w_{n}
\end{array}\right] \\
& S=A \otimes W^{T}=\left[\begin{array}{c}
S_{1} \\
S_{2} \\
\cdot \\
S_{m}
\end{array}\right]
\end{aligned}
$$

Table shows the composite priorities for the 6 rivers using FAHP method.

\begin{tabular}{|c|c|c|c|c|c|c|}
\hline & The Godavari & $\begin{array}{c}\text { The } \\
\text { Krishna }\end{array}$ & $\begin{array}{c}\text { The } \\
\text { Cauvery }\end{array}$ & The Tungabhadra & The Bharathapuzha & $\begin{array}{c}\text { The } \\
\text { Bhavani }\end{array}$ \\
\hline Water quality & 0.037 & 0.073 & 0.019 & 0.030 & 0.010 & 0.018 \\
\hline Water quantity & 0.083 & 0.076 & 0.067 & 0.059 & 0.005 & 0.073 \\
\hline Land use & 0.024 & 0.148 & 0.094 & 0.091 & 0.077 & 0.089 \\
\hline Economy & 0.055 & 0.110 & 0.063 & 0.068 & 0.020 & 0.008 \\
\hline Overall & 0.211 & 0.555 & 0.316 & 0.188 & 0.248 & 0.129 \\
\hline Rank & 4 & 1 & 2 & 5 & 3 & 6 \\
\hline
\end{tabular}

Table 1.6: Composite priorities using FAHP. 
Step 8: Choosing the highest ranking from the set of alternatives.

Though understanding of the geomorphologic, geological and hydro geological features are necessary pre requisites for selecting the area suitable for and the type of artificial recharge. The suitability of an area for artificial recharge characteristics and aquifer parameters. Availability of unsaturated dried up aquifer zones and ground water quality is other important consideration in this regard. As far as south area is concerned majority of the area is covered by any cut lands. Numerous rivers and canals cuddling across the levee complexes charge the water table aquifer. Areas other than levees are covered by clayey formation. Hence, de-silting of existing ponds and Ooranies are recommended for artificial recharge. Alternative with the highest priority value will be chosen. Based on the overall composite value in Table 1.7, The Krishna is the best-ranked river followed by the Cauvery, the Bharathapuzha, the Godavari, the Tungabhadra and the Bhavani. Krishna River also scored the highest composite priority value on water quality, land use and economy. Therefore, Krishna River will be chosen as the most efficient use of river system in South India. Different situations that lead to uncertainty are unquantifiable information, incomplete information, non-obtainable information and partial ignorance. Uncertainty in multi criterion decision making (MCDM). Environment mainly occurs in two situations while assessing weights of the criteria evaluating the alternatives with respect to the criteria. Fuzziness is expressed as "not sharply focused, clearly reasoned or expressed; confused; lacking of clarity; blurred". Degree of similarity values vary from zero to one. The alternative with the highest degree of similarity is considered to be the best. Fuzzy analytic hierarchy process (FAHP) is an extension of Analytic Hierarchy process (AHP) in fuzzy environment. In the case AHP, elements of pair wise comparison matrix lie between 1 and 9 , whereas in the case of fuzzy AHP these are fuzzy numbers.

\begin{tabular}{|c|c|}
\hline RIVERS & FAHP \\
\hline THE GODAVARI & 4 \\
\hline THE KRISNA & 1 \\
\hline THE CAUVERY & 2 \\
\hline THE TUNGABHADRA & 5 \\
\hline THE BHARATHAPUZHA & 3 \\
\hline THEBHAVANI & 6 \\
\hline
\end{tabular}

Table 1.7: Comparison results of river ranking

\section{CONCLUSION}

This work has focused on handling vague data in the decision making process. Various aspects of river basins to find the most efficient use of water system have been proposed in this study. The proposed FAHP approach is found to be able to deal with vague data using fuzzy triangular numbers. It is claimed that the proposed technique not only can be used to address the problem with vague data acquisition, but it can also represent the relative level of risk and level of confidence that the DMs may give. The TFN used in this study can also be used to represent linguistic variables should the DMs feel uncomfortable to use interval judgment values. Based on the available data, Krishna River is found to be the best river to be chosen should a development project is to be made which emphasize on efficient use of river system.

\section{Reverences:}

[1] Fuzzy sets and fuzzy logic theory and applications. George j. kir and Bo Yuan. PHI learning private limited 2012.

[2]Gesiri G., "Pemeringkatan Sungai-sungai Selatan Johor menggunakan perisian HIPRE3+".Tesis Projek Sarjana Muda, Fakulti Kejuruteraan Awam, Univeristi Teknologi Malaysia, (2005).

[3]Efendigil, T., Onut, S., Kongar, E., "A holistic approach for selecting a third-party reverse logistics provider in the presence of vagueness", Computers \& Industrial Engineering, Vol. 54, (2008), pp. 269-287.

[4]Ho, W., "Integrated Analytic Hierarchy Process and Its Applications - A literature review", European Journal of Operational Research, Vol. 186, No. 1, (2008), pp. 211-228.

[5] Hajkowicz, S., Collins, K., "A review of multiple criteria analysis for water resource planning and management", Water Resources Management, Vol. 21, No. 9, (2007), pp. 1553-1566.

[6] Balteiro-Diaz L, Romero C., "Making forestry decisions with multiple criteria: A review and an assessment", Forest Ecology and Management, 
Vol. 255 (2008), pp. 3222-3241.

[7] Steuer, R. E., Na, P., "Multiple criteria decision making combined with finance: A categorized bibliographic study", European Journal of Operational Research, Vol. 150, No. 3, (2003), pp. 496-515.

[8] Vadya, O.S., Kumar, S., “Analytic hierarchy process: An Overview of applications”, European Journal of Operational Research, Vol. 169, No. 1, (2006), pp. 1-29.

[9] M. Ashari, A., S. Zaiton, M.H., Supiah, S., “AI Applications in MCDM: A Review”, Post Graduate Research Seminar, 2008 (PARS’08), Faculty of Computer Science \& Information Systems, Universiti Teknologi Malaysia, July 2-3, (2008).

[10] Bottani, E., Rizzi, A., "An adapted multi-criteria approach to suppliers and products selection-An application oriented to lead-time reduction", Int. J. Production Economics, Vol. 111, (2008), pp. 763-781.

[11] Buyukozkan, G., Feyzioglu, O., Nebol, E., "Selection of the strategic alliance partner in logistics value chain", Int. J. Production Economics, Vol. 113, (2008), pp. 148-158.

[12] Cascales, M. S. G., Lamata, M. T., "Fuzzy Analytical Hierarchy Process in Maintenance Problem”, IEA/AIE 2008, LNAI 5027, (2008), pp. 815-824.

[13] Pan, N.-F., "Fuzzy AHP approach for selecting the suitable bridge construction method", Automation in Construction, Vol. 17, (2008), pp. 958965.

[14] Sheu, J. B., “A hybrid neuro-fuzzy analytical approach to mode choice of global logistics management”, European Journal of Operational Research, Vol. 189, (2008), pp. 971-986.

[15] Tsai, M. T., Wu, H. L., Liang, W. K.., "Fuzzy Decision Making for Market Positioning and Developing Strategy for Improving Service Quality in Department Stores", Quality \& Quantity, Vol. 42, (2008), pp. 303-319.

[16] Wu, C. R., Lin, C. T., Chen, H. C., "Integrated environmental assessment of the location selection with fuzzy analytical network process", Quality and Quantity, Online first, (2008).

[17] Huang, C. C., Chu, P. Y., Chiang, Y. H., “A fuzzy AHP application in Government - sponsored R\&D project selection”, Omega, Vol. 36, No. 6), (2008), pp. 1038(15).

[18] Lee, D., Lee, C., Pietrucha, M. T., "Evaluation of driver satisfaction of travel information on variable message signs using fuzzy aggregation", Journal of Advanced Transportation, Vol. 42, No. 1, (2008), pp. 5(18).

[19] Chang, C. W., Wu, C. R., Chen, H. C., "Using Expert Technology to Select Unstable Slicing Machine to Control Wafer Slicing Quality via Fuzzy AHP”, Expert Systems with Applications, Vol. 34, No. 3, (2008), $\quad$ pp. 2210-2220.

[20] Chang, C W, Wu C R, Lin C T, Chen H C., "Evaluating and controlling silicon wafer slicing quality using fuzzy analytical hierarchy and sensitivity analysis", Int J Adv Manuf Technol Vol. 36, (2008), pp. 322-333.

[21] Chang, T. -H., Wang, T.-C., "Measuring the success possibility of implementing advanced manufacturing", Expert Systems with Applications (2008), doi:10.1016/j.eswa.2008.03.019

[22] Chen, M. F., Tzeng, G. H., Ding, C.G., "Combining Fuzzy AHP with MDS In Identifying The Preference Similarity of Alternatives”, Applied Soft Computing, Vol. 8, No. 1, (2008), pp. 110-117.

[23] Chen Y, Qu L., "Evaluating the Selection of Logistics Centre Location Using Fuzzy MCDM Model Based on Entropy Weight, Proceedings of the 6th World Congress on Intelligent Control and Automation, June 21 - 23, (2006), Dalian, China.

[24] Dagdeviren, M., Yuksel, I., "Developing a Fuzzy Analytic Hierarchy Process (AHP) Model for Behavior-based Safety Management", Information Sciences, Vol. 178, No. 6, (2008), pp. 1717-1733, 200

[25] Nagahanumaiah, Subburaj, K., Ravi, B., "Computer Aided Rapid Tooling Process Selection and Manufacturability Evaluation for Injection Mold Development", Computers in Industry, Vol. 59 (2), (3), (2008), $\quad$ pp. 262-276.

[26] Duran, O., Aguilo, J., "Computer-aided Machine-tool Selection Based on A Fuzzy-AHP Approach", Expert Systems with Applications, Vol. 34, No. 3, (2008), pp. 1787-1794.

[27] Onut, S., Kara, S.S., Efendigil, T., “A hybrid fuzzy MCDM approach to machine tool selection”, J Intell Manuf., Vol. 19, N. 4, (2008), pp. 443453.

[28] Yang, J. L., Chiu, H. N., Tzeng, G. H., "Vendor selection by integrated fuzzyMCDM techniques with independence and Interdependence, To appear in Information Sciences, Accepted manuscript. (2008).

[29] Wang YM, Luo Y, Hua Z., "On the extent analysis method for fuzzy AHP and its applications”, European Journal of Operational Research, Vol. 186, (2008), pp. 735-747.

[30] Saaty T L, Kearns K P., Analytical Planning - The organizations of Systems, Pergamon Press, pp.19-62. (1985)

[31] Supiah, S., NorBaharim, H., Azmi, A.R., Gesiri, G., "Southern Johor River Ranking Using HIPRE 3+", International Conference on Reservoir Operation and River Management, Guangzhou \& Three Gorges, China, (2005).

[32] DID, Department of Irrigation and Drainage of Malaysia, http://www.water.gov.my/index.php?option=com_content\&task=view\&id=1 6\&Itemid=265 ( $5^{\text {th }}$ February, 2009)

[33] Zopounidis, C., Stewart, T. J., Doumpos, M., Editorial, J Glob opt. (2008).

[34] Hajkowicz, S, Higgins, A., "A comparison of multiple criteria analysis techniques for water resource management", European Journal of Operational Research, Vol. 184, (2008), pp. 255-265.

[35] Hajkowicz, S., Collins, K., "A review of multiple criteria analysis for water resource planning and management", Water Resources Management, Vol. 21, No. 9, (2007), pp. 1553-1566.

[36] Phillips-Wren, G., "Assisting Human Decision Making with Intelligent Technologies", Proceedings of the 12th international conference on Knowledge-Based Intelligent Information and Engineering Systems. Part I. Springer-Verlag. Lecture Notes In Artificial Intelligence; Vol. 5177, (2008), pp. 1-10. Keynote Lectures.

[37] Ho, W., "Integrated Analytic Hierarchy Process and Its Applications - A literature review", European Journal of Operational Research, Vol. 186, No. 1, (2008), pp. 211-228.

[38] Hajkowicz, S.A., Wheeler, S. A., "Evaluation of Dairy Effluent Management Options Using Multiple Criteria Analysis", Environmental Management, Vol. 41, (2008), pp. 613-624.

[39] Hashimoto, T.(1980). Robustness, reliability, resilience and vulnerability criteria for water resources planning. Ph.D. dissertation, Cornell Univ., Ithaca, N.Y.,USA.[40] Hashimoto, R., J.R. Stedinger and D.P. Loucks (1982). Reliability, resiliency and vulnerability criteria for water resources 
system performance evaluation. Water resources Research, vol.18, No.1.

[41] Aller, L., Bennett, T., Lehr, J.H. \& Petty, R.J.(1985) DRASTIC: A Standardized System for Evaluating Ground Water pollution Potential Using Hydrogeological Settings. EPA/600/2-85/018.

[42] Bolton, K. F. \& Curtis, F. A. (1990) An environmental assessment procedure for siting solid waste disposal sites. Environmental Impace Assessment Review 10, 285-296.

[43] Hamed, M. M., Conte, J.P. \& Bedient, P.B. (1995) Probabilistic screening tool for ground water contamination assessment. Journal of Environmental Engineering (ASCE) 121(11), 767-775.

[44] CHEN Shou-yu, "Theory and method of variable fuzzy set in water resources and flood control system," Dalian: Dalian University of Technology Press, 2005, pp:226-235.

[45] LI Ya-wei, CHEN Shou-yu and FU Tie, "Comprehensive evaluation of water resource carrying capacity based on fuzzy recognition," Advances in Water Science, vol. 16, 2005, pp:726-729.

[46] XU Pengzhu and QIN Boqiang, "Degeneration cause, restoration and reconstruction imagination for the ecosystem of lakeside Zone of Taihu Lake," water resources protect, vol. 18(3), 2002, pp, 31-36.

[47] Chen S.H. (1985) Ranking fuzzy numbers with maximizing set and minimizing set. Fuzzy Sets and Systems 17. 113-129.

[48] Balteiro-Diaz L, Romero C., "Making forestry decisions with multiple criteria: A review and an assessment", Forest Ecology and Management, Vol.255 (2008), pp. 3222-3241.

[49] Steuer, R. E., Na, P., "Multiple criteria decision making combined with finance: A categorized bibliographic study", European Journal of Operational Research, Vol. 150, No.3, (2003), pp. 496-515.

[50] Bender MJ, Simonovic SP. 2000. A fuzzy compromise approach to water resource systems planning under uncertainty. Fuzzy sets and Systems 115:35-44.

[51] Chen SM, 1994. A new method for handling multicriteria fuzzy decision making problems. Cybernetics and System 25:409-420.

[52] Cornell G. 2001. Visual Basic 6 from the Ground up. Tata McGraw-Hill: New Delhi, India.

[53] Heyder WE, Gates TK, Fontane DG. Salas JD. 1991. Multicriterion strategic planning for improvd irrigation delivery. II: application. Journal of Irrigation and Drainage Engineering 117:914-934. 